\title{
Russian Province in a Power Deficit (Regional Stories)
}

\author{
Skiperskikh Aleksandr Vladimirovich* \\ Bunin Yelets State University, Kommunarov St., 28, 399770Yelets, Russia
}

\begin{abstract}
This article discusses how a power deficit can be felt in the Russian province. The uneven economic development of the territory of Russia, large gaps between the center and the province give rise to the practice of a rapid centralization and exodus from the peripheral territories. This practice means the emergence of a deficit of infrastructure, which, in turn, causes a deficit of the power itself, which must serve this infrastructure. At the same time, the weakening of the bureaucratic pressure can also have its advantages for the inhabitants of the Russian provinces, whose economic freedom can be constructed in rather anarchic discourses. The lack of power means the emancipation of a person, his greater independence and variability in life forms. The article is based on the author's observations and impressions, suggesting the field studies of various cases of perception of the power deficit in the Russian province.
\end{abstract}

\section{Introduction}

Power is everywhere, but it is not evenly distributed in space. The concentration of power can be extremely high the moment we see its action, as well as the effects it produces. The concentration of power is manifested not only at the moment of a directed signal of the authority, but also when, as it seems to us, power is at rest. But even at this very moment, one can assess its physical capabilities by looking at the scale of its residences government quarters, mansions, security staff. Power is manifested in its propensity for gigantism. It is the architecture of power that shows the difference between power and the rest of society, highlighting the totalitarian nature of the political space.

Power reaches its highest concentration in the Center, in the capital, where it is personally present. But if somewhere there is an excess of power, then in another place its deficit may arise. This political rule fully works in relation to modern Russia, whose political space seems to be very uneven. If power is drawn to the center, this means that there will always be a deficit in the province. In this article we will discuss the reasons for the appearance of such a deficit, as well as in what situations this deficiency can be embodied. It should be understood that the deficit of power in a province can also be viewed in the context of its economic prospects, because power is always greater where there is a full life, where blood is actively circulating through the body of the state like Hobbesian Leviathan - the metaphorical money.

\footnotetext{
"Corresponding author: pisatels@mail.ru
} 


\section{Excessive centralization and the consequences thereof}

Russia's excessive centralism is inevitably projected onto the economic images of the regions. The regions are significantly behind Moscow in terms of both economic attractiveness and cultural diversity. The author of the paper had to pay attention to this while working at the Perm campus of National Research University - Higher School of Economics. Bright and talented students, with good English, did not see themselves in Perm, and as soon as possible sought to use the student mobility channels to leave for Moscow or St. Petersburg.

Without denying the enormous role of the megacities in the economic and cultural life of modern Russia, it should be noted that the Russian space is by no means limited to only large cities and capitals. Russia seems to be different, complexly structured, which, in its own way, organizes the space of power. In a complex combination of the opposites - urban and rural, western and eastern, northern and southern, a bizarre Russian text is constructed. Different Russia, united within federal districts and historically established regions, is today united into a single entity. But there is no need to distinguish between its incredible differences, its completely disparate economic capital. Pyotr Kropotkin, being duty-bound and carrying out missions in Siberia and the Far East of the Russian Empire, admitted that he made an anarchist choice solely because of the accumulated observations about the differences in Russian administrative, political and economic practices, in fact, questioning any possibility of overcoming them [1].

"St. Petersburg is not Russia," once ironically noted Georgy Gachev, although the authorities may think in a completely different way, assuming that it is they who, by their essence, are representative of Russia to others [2]. Let us recall the senator from A. Bely's "Petersburg" novel, who moved around the capital in a black lacquered carriage, and was rather disgusted with the people around him. A. Bely perfectly conveyed these feelings of power, this artificial concern, the feeling of incredible self-importance: "He felt like the carcass from which Russia was falling off' [3].

While the authorities may be characterized by the centripetal moods, on the contrary, the opposite processes can be observed for the society. So, during the all-Russian population census in 2010, 4116 people identified themselves as the "Siberians" [4]. Indeed, in the light of recent events, Russia is also Khabarovsk, where power is present as well. Is it possible to refuse this city if it is present on the five thousandth bill? Indeed, the signals of power, due to Russia's unique geographic specifications, reach Khabarovsk, having already largely been distorted and weakened. The Khabarovsk protests show that on the part of the center, one can see some arrogance towards the periphery, a consumer attitude towards it. This is confirmed by the increasing cases of protests against the construction of garbage plants, dumps and landfills in the constituent entities of the Russian Federation. The situation around the Shies station in the Arkhangelsk region may be a fairly resonant case. In 2018, there was a confrontation between the environmental activists and the local residents, on the one hand, and the authorities planning to build a landfill for garbage disposal, on the other. At the end of August 2020, the confrontation in Bashkortostan escalated between the authorities and the protesters against the development of a unique shihan. The center is bathed in luxury and blessings, at the same time as the province must pay for the center's high level of comfort.

Compared to the prosperous development dynamics of some Russian megalopolises, the Russian province is now gradually becoming empty. The exodus of the population from the Russian province, caused by objective reasons - the quality of medical care, the closure of schools, the lack of proper transport infrastructure, leisure, etc., suggests that the power itself comes from the province. The local elite understands that the problems facing the provincials, sooner or later, may be open to themselves. Looking at some of the heads of 
the rural administrations today, you involuntarily begin to understand what a serious staff shortage the municipal and regional authorities are facing today.

The institutions of power that remain in the modern Russian province are often the lightweight copies of the municipal administrations, with the only difference that the functions of the head of the administration are much more expanded. The structure of the power in the provinces, in principle, can repeat the political design that is used in the more authoritative authorities. Therefore, in the provinces, as I. Isaev notes, "there are already familiar figures of a lord and a slave, a leader and a warrior, a priest and a bureaucrat" in the bodies of government [5]. At the same time, as already noted, the authorities can hardly afford to maintain such a staffing table in the modern conditions. Deficiency leads to overlapping functions. The power deficit in a province has its own special effects. At the same time, the provinces, despite the extinction of economic life, have their own charm, which cannot but capitalize on in the conditions of the post-industrial world improving.

\section{The province as a space for salvation}

The lack of power can be partly beneficial for some social groups who, by chance, ended up in the provinces to implement their life strategies - either of their own free will, or thanks to the repressive machine. For some, the sedentary nature of life in the provinces is quite a natural practice. In favor of the province, in favor of slow chronotopes, the very belonging of a person to Russian culture speaks [6].

Certainly, power scarcity helps maximize resistance. A fairly free, marginal way of life becomes quite an affordable practice. In this case, we can't help but mention R. Nozick and his concept of the "minimum state" [7]. It would seem that the province acts as an optimal, almost saving space for those who were burdened by an excessive supervision of the repressive institutions of the totalitarian machine. Let's remember the provincial exiles of A. Pushkin. It is in this fertile soil, in restricted, but, nevertheless, free conditions, that he created his wonderful texts. Let us recall the exile to Cherdyn and Zadonsk by $\mathrm{O}$. Mandelshatam. In this case, the real province was revealed to the poet, because in 1935 large cities were closed for him to live. Something similar can be said about M. Bakhtin, after the Kustanai exile, who taught in the decent Saransk. Some contemporaries of M. Bakhtin (in particular, G. Gachev and S. Bocharov) are inclined to believe that the philosopher survived precisely because of this exile, because the capital cities at that time would have looked much more dangerous for him. By removing the intellectual from the capital cities, depriving him of communication, influence on the masses, the authorities seem to be solving the issue of his social isolation. But, as practice shows, in silence, in solitude, practically outside, an intellectual can accumulate the potential to influence public minds, and preserves himself for the world culture. The frontal resistance to the political machine is already meaningless - the intellectual can act remotely.

The practice of expulsion to the provinces extends not only to the intellectuals who have complicated relations with the ruling regime, but also to quite ordinary people. So, during the 1980 Olympics in the USSR, large cities were cleared of unreliable elements and outcasts that could darken the enthusiastic and victorious feeling of the Soviet holiday. The USSR is a huge archipelago of colonies and camps. Once a guide, during a visit to the Perm-36 camp, talked about the special regime of being in the colony, about the inability to get in touch with the mainland. In such a situation, quite by chance, bird watchers could establish their approximate location by the behavior of birds, their specific type of birds.

The metropolitan government remembers the province at a time when it has to defend its own interests. After the reform of the Federation Council, V. Putin unexpectedly found that the majority of senators have a Moscow and Leningrad registration, although the senators represent the interests of the regions. Their prestigious position forced them to 
choose the complex schemes of incorporation into the regional systems of power, to be elected as deputies of the ordinary rural administrations. In this case, we see that the deficit of power is used by the political elite itself, which manages to quietly implement the strategy of political legitimation without attracting too much attention. Along with this, the lack of power in the provinces is understood "from above" as something inevitable, as quite ordinary characteristics of the periphery, the absence of strong influential channels for lobbying the interests of the province in the highest echelons of the power. The modern regional political design is built in such a way that practically any issue that arises at the local level will be resolved in the regional center. For the provincials, the capital of the region is today like a magic kingdom, not to mention Moscow itself. The center is a source of benefits and a fast elevator that allows you to move through space. In Russia, almost all air travel is carried out through Moscow, which implies both a forced and a quite desirable arrival to the Center. Russian megacities may even be less interesting for the implementation of life strategies than Moscow and St. Petersburg. During his work in the Urals, the author observed a steady trend of educational migration to Moscow and St. Petersburg from Perm. Any metropolis in Russia has a provincial tinge in comparison with them. "There is all the power in Moscow," one of the heroes of the "Brat" film by A. Balabanov will say, showing Moscow's preferred position relative to St. Petersburg, despite the steadily replicated myths of the 2000s about the importance of St. Petersburg origin for career development in the corridors of power.

In modern Russia, the province is understood as a fall-back position. The Center's interest in the province as a space of salvation can also be seen in the escapist practices. Trips to nature, to the plain air, to the dacha, to the village, visiting gastronomic and the newsworthy events in the regions are the modern attempt to compensate for the lack of freedom that is present in the Center. In this kind of excapism, one can see the satiety of the pressure of power, its searing control. At the same time, the residents of the capital are well aware that they can afford the Russian province today, because the level of salaries, say, in Moscow and Vladimir region is completely incomparable. Recently, in the provincial universities, one can see an increase in applicants from the capital, for whom it is important to obtain a state-funded place. In the provinces, it becomes much easier to be credited to the "state-funded place" than in the megalopolis.

The relevance of the province, in contrast to the Russian megacities, clearly manifested itself during the COVID pandemic. Demand for suburban real estate is growing. Moscowite could stand out in the provinces with their excessive self-care for the provincial - the obligatory mask, gloves, antiseptics. Sanctions for violation of the sanitary regime in Moscow were much harder than in the anarchist province. Of course, in the provinces, it is much more difficult to urge the population to comply with the rules. It is not clear who in this case will have to write out a fine, because the social field in the province is rather tight. It is difficult to imagine that an ordinary person can be subject to a fine equal to his monthly salary.

\section{Provinces and alternative institutions}

Reducing the bureaucratic coercion contributes to a situation in which being becomes more and more existential. Power is less and less inclined to act as a regulator of the daily practices of human life. As you reach the province, the signal of power generated in the center weakens significantly, reaching the provincial space in a muffled and even distorted form. Thus, the "excessive power", conceptualized by the German communication theorist $\mathrm{N}$. Luhmann, is transformed into "insufficient" power [8]. In this sense, master classes were announced during one of the tourist events in Lipetsk region, during which visitors were given "the opportunity to learn for free unique skills that will help to survive in the event 
that the modern benefits of the civilization suddenly disappear: grinding grain in a millstone, using a grab and the simplest weights, forging nails, melting silver in a crucible and even medieval writing and minting coins. Particular attention will be paid to the personal hygiene. The natives of Lipetsk will be taught to soak linen in a solution of ash, beat it with a wooden mallet, rinse it in the ice hole and iron it with a rolling pin "[9]. In the Novgorod region, with the help of the rural postmen, the authorities are trying to solve the problems of infrastructure development. The functionality of the postal service is significantly expanding while reducing the bureaucratic mass. Not only will the postmen compensate for the lack of the pharmacies in the rural areas and deliver medicines to the homes, but they will also provide medical assistance if necessary [10]. In this sense, it is understandable why the opening of even a small rural health post is an important event for the regional authorities today, and why the heads of the regions are in a hurry to use this occasion in order to remind the public of their activities for the province.

Nevertheless, in the case of Lipetsk and Novgorod examples, we are faced with a situation where a rollback to some archaic forms of life, to primitive practices of maintaining everyday life, in fact, is an indicator of a lack of power, its inability to quickly and effectively solve one or another problem. The protracted terms of reconstruction of the infrastructure facilities, unscrupulous contractors and other problems today do not look surprising to the authorities in the Russian province. A deficit of power means a deficit of bureaucracy, because even bureaucratic services are capable of exerting the significant pressure on the public body. There is nothing surprising in what M. Foucault once reminded of. After all, the relationship of power is holding it in a stranglehold. They seize it, stigmatize, drill, torture, compel it to work, force to participate in the ceremonies, to produce the signs" [11]. In spite of such repressive practices, alternative institutions are being created, legitimized "from below".

In comparison with the megalopolises, a province in Russia seems to be a special space. There is another legal field therein. The lack of power in the provinces, which we are discussing in this text, leads to a situation where the prescriptions of the authorities and the already formulated "rules of the game" are no one to be controlled by. In this case, the rules are often violated, and the lack of control of the authorities, the absence of fear due to nonobservance of any norm turn into a traditional mode of behavior. In such a cultural and spatial womb, a person is brought up who consciously and unconsciously allows himself to live in a constant holiday of disobedience.

Despite the spaciousness of space, any person has a latent dream of the escaping horizon, of moving forward, of discovering something that contributes to the acquisition of sufficiently free forms of existence [12]. In Russian culture, there are many examples of how it is in the provinces that the legitimization of forms of free life, having been romanticized and poeticized in Russian folklore, classical literature, and drama, takes place. The emergence of power in such a situation, the replenishment of its deficit, means instant problems for a person. Let us recall at least the well-known text by M. Saltykov-Shchedrin about a man who fed two generals, which we once examined for possible projections on the real politics of modern Russia [13].

In teaching practice, the author sometimes has to ask students about the perception of freedom in the provinces. Students need to give an example of what can be done in the provinces at a time when the same will be difficult to imagine in a capital city. Students answer that in the village you can freely drive a car without a license, without appropriate documents, without insurance, registration numbers, turning a blind eye to traffic rules, etc. Provincial nihilism does not seem accidental to us - it reveals in its own way the problem of the deficit of power institutions in the Russian provinces. In the Russian hinterland, for sure, not all owners of smooth-bore weapons seek to renew their license as soon as possible, especially in light of the significant increase in fees and cost of medical 
examination, for which it is necessary to visit a more or less large clinic or medical center. Power deficit means control deficit. If we assume that the power is expressed in the ability to gradually control a person, then such a control is hardly possible in the provinces. In the Russian provinces, you can still find drinking well columns, chickens and geese walking along the roads. People cross the road wherever they want, or they park as they want, completely unconcerned about paying for parking spaces and the fear of costly buying a car out of a parking lot. Modern alternative institutions in the Russian provinces function in the same logic, as if they would have developed back in the Russian Empire or under the USSR.

In N. Leskov's "Robbery", the province is a convenient space for robbers. A provincial town in Oryol province is the optimal chronotope for the implementation of the criminal intentions. In "Arseniev's life" by I. Bunin, the beliefs about the robbers who were waiting for the late merchants on the roads in deep ravines are romanticized, when "at their cherished hour, from various secret gullies and water cisterns, good fellows came out under the road, hearing with a sensitive ear in the silence of the night the distant crying of a bell or the sound of a simple cart "[14]. The province's historical predisposition for the illegal activities is verified by numerous reports from the Ministry of Internal Affairs about the attacks on the truckers and motorists in the 1990s. In "Boomer-2" film (dir. by P. Buslov), an expensive car is taken from the main character on a provincial, secondary road. The anarchy of the province is still experienced by the motorists when faced with a lack of infrastructure. It is no coincidence that some motorists traveling to the northern regions of the Russian Federation in the Northern Urals take a fairly large supply of gasoline, because there may be no gas stations in those places where they have to pass. Gasoline is purchased from private individuals. They also rent housing if necessary. Naturally, in such practices one does not have to rely on their clear legal support - sellers work by themselves, without providing any documents.

\section{In lieu of conclusion}

Thus, the province in Russia is initially perceived as a space that is different from the Center. The difference between the province and the center is checked by differences in the institutions of power - their structure, quantitative characteristics and functions. At the same time, both the center and the province are still present in a single political framework and are linked by the establishment of power that develops the "rules of the game".

Modern Russia appears to be a state with uneven economic and spatial development of its constituent parts. Significant differences in the ways of economic life of the constituent entities of the Russian Federation and individual territories indicate serious differences in legal regimes. Hence, the high pressure of power on a person in Russian megalopolises and the oversaturation of institutions of power in the center naturally create a kind of emptiness in the periphery. The objective deficit of power in the provinces, on the one hand, contributes to the emancipation of a person, largely freeing him from relentless bureaucratic pressure. True, on the other hand, the lack of power also indicates a lack of infrastructure, which cannot be attributed to the factors that make the provincial space attractive for life.

\section{References}

1. P.A. Kropotkin, Siberian notebooks, (1862-1866), 347

2. G. Gachev, National images of the world. Lecture course, 388 (1998)

3. A. Bely, Petersburg, 448 (2016) 
4. There are almost 412 times more "Siberians" in Russia over the past eight years Rosstat data, https://tayga.info/

5. I.A. Isaev, PoliticaHermetica: The Hidden Aspects of Power, 566 (2003)

6. A. Skiperskikh,SotsiologicheskoeObozrenie,16 (2), 180(2017)

7. Nozick R. Anarchy, State and Utopia, 424 (2008)

8. N. Luhmann, Power, 130 (2001)

9. The art of surviving: residents of Lipetsk will be prepared for a global catastrophe (2019), https://most.tv/

10. Postmen in the Novgorod region will be trained to provide medical care (2018),https://iz.ru/

11. M. Foucault, Discipline and Punish. The birth of the prison, 39 (1999)

12. A.V. Skiperskikh, Discourse-Pi,3-4, 32(2018)

13. A.V. Skiperskikh, Political elites and masses. M. Saltykov-Shchedrin, Theories and problems of political research,1, 67(2012)

14. I.A.Bunin, Arseniev's life. Stories and novels, 98 (1989) 